\section{Measuring the systemic effects of inhaled beclomethasone: timed morning urine collections compared with 24 hour specimens}

\author{
H David McIntyre, Charles A Mitchell, Simon D Bowler, John G Armstrong, \\ Jan A Wooler, David M Cowley
}

\begin{abstract}
Background - Inhaled glucocorticoid therapy has systemic effects including hypothalamic-pituitary-adrenal (HPA) suppression. The optimal test for detecting these effects has not been defined.

Methods - Timed urine collections and 09.00 hour plasma cortisol levels were obtained from 12 normal volunteers receiving inhaled placebo, beclomethasone (BDP) 800 or $2000 \mu \mathrm{g} /$ day. The 24 hour urine samples were collected as follows: first hour after waking (hour 1), the next two hours after waking (hours 2 and 3), remainder of day, and overnight, with results expressed as urine cortisol/creatinine (UCC) ratios and as hourly cortisol output in the timed collections. Twenty four hour urinary cortisol excretion was also calculated. Medication was blinded and given in random order with a washout period of at least 11 days between each treatment arm.

Results - None of the UCC ratios changed with BDP $800 \mu \mathrm{g} /$ day. UCC ratios at hour 1 , hours 2 and 3, and overnight, and 24 hour urinary free cortisol excretion were reduced after BDP $2000 \mu$ g/day, whilst remainder of day UCC ratio and the plasma cortisol level did not change significantly. Cortisol output showed similar changes. In a follow up study BDP $1400 \mu \mathrm{g} / \mathrm{day}$ also reduced UCC ratios for the first two hours after waking.

Conclusions - UCC ratios are as sensitive as the more cumbersome $\mathbf{2 4}$ hour urinary free cortisol excretion, and more sensitive than single morning plasma cortisol measurements, in detecting the effects of inhaled beclomethasone on the HPA axis. (Thorax 1995;50:1280-1284)
\end{abstract}

Keywords: beclomethasone, urinary cortisol, hypothalamic-pituitary-adrenal axis, asthma.

Respiratory Medicine,

Princess Alexandra

Hospital,

Woolloongabba,

Queensland 4102,

Australia

C A Mitchell

J G Armstrong

J A Wooler

Reprint requests to:

Dr H D McIntyre.

Received 6 December 1994

Returned to authors

28 February 1995

Revised version received

2 June 1995

Accepted for publication

22 August 1995 Inhaled corticosteroid therapy is firmly established as a major form of preventative treatment for asthma. ${ }^{1}$ In addition to this beneficial effect, inhaled steroid treatment may have unwanted systemic effects, including reduction in bone formation as shown by reduced osteocalcin concentrations, ${ }^{23}$ and suppression of the endogenous hypothalamic-pituitary-adrenal (HPA) axis. ${ }^{4}$ Commonly used measures of HPA effects of inhaled steroids have included 24 hour urinary free cortisol excretion, ${ }^{4-11}$ timed plasma cortisol measurements, ${ }^{457-12}$ and alterations in the cortisol response to tetracosactrin. ${ }^{471011}$ Brown et al, ${ }^{10}$ using the response to insulin hypoglycaemia as the "gold standard" for assessing HPA function in a group of 11 patients with subnormal or borderline responses to other tests, described good correlations between this measure and the 24 hour urinary free cortisol (UFC) excretion and tetracosactrin test results. The metyrapone test $^{49}$ has been suggested as a sensitive means of detecting HPA suppression during inhaled steroid therapy. All of these tests have practical disadvantages such as relative insensitivity (plasma cortisol), ${ }^{4}$ need for complete urine collection (24 hour UFC), or need for multiple blood samples before and after stimulation of cortisol production (tetracosactrin test, metyrapone test). The "gold standard" insulin hypoglycaemia test is invasive, unpleasant, and labour intensive, with medical supervision mandatory, making it impractical for repeated testing of large numbers of subjects.

Urinary cortisol excretion in morning urine samples, expressed as the concentration ratio of cortisol to creatinine, has been shown to be a useful screening test in cases of suspected adrenal hypo- or hyperfunction. ${ }^{13}$ Such collections have obvious practical advantages for repeated testing, including the possibility of home collection. The current study was designed to test the hypothesis that timed urine samples would prove as sensitive as 24 hour urinary free cortisol excretion and other nonstimulated measures of endogenous cortisol secretion in detecting the HPA effects of inhaled steroid.

\section{Methods}

The studies were considered and approved by the institutional medical ethics committees.

\section{STUDY 1}

Subjects

Twelve normal men participated after receiving study and giving writter None of the subjects suffered from any chronic illness (including asthma), nor were they taking any other medication at the time of the study. were normal in all cases. Subject characteristics expressed as mean (range) were: age 34 (24-53) years; weight $77 \cdot 8(63-110) \mathrm{kg}$; body mass index $(\mathrm{BMI}) 24 \cdot 0(19 \cdot 4-30 \cdot 1) \mathrm{kg} / \mathrm{m}^{2}$. Baseline full blood count and biochemistry 
Protocol

The study was randomised, placebo controlled, and double blind in design. Subjects inhaled beclomethasone dipropionate (BDP) in daily doses of 0 (placebo $\times 4$ puffs twice daily), $800 \mu \mathrm{g}(100 \mu \mathrm{g} \times 4$ puffs twice daily), and $2000 \mu \mathrm{g}(250 \mu \mathrm{g} \times 4$ puffs twice daily $)$. Metered dose aerosol inhalers were used without any spacer device and without mouth rinsing. Each dose period lasted 10 days, with a minimum of 11 days washout between successive dose periods. Subject compliance was estimated by weighing the metered aerosol canisters before and after each dose interval. Blood and 24 hour urine samples were collected on the day before starting each treatment phase and on the tenth day of treatment as follows.

On each collection day subjects fasted until blood was drawn for plasma cortisol assay (at 09.00 hours \pm 30 minutes). The 24 hour urine collections were collected as four separate samples: (1) first hour after waking (hour 1); (2) next two hours after waking (hours 2 and 3); (3) remainder of day (until bedtime); (4) overnight.

The times of waking and retiring were not regimented, but remained constant for each subject over the course of the study. Subjects voided on rising, then inhaled the study drug and commenced the hour 1 urine collection. All hour 1 specimens were collected in the fasting state.

\section{STUDY 2}

After reviewing the results of the first study, a further double blind, randomised, placebo controlled experiment was performed to examine the effects of an additional dose level of BDP $(1400 \mu \mathrm{g} /$ day $)$. Ten healthy men participated in this study (six had also taken part in study 1). Mean (range) characteristics of the subjects were: age 38 (23-56) years; weight $76 \cdot 2(65-89) \mathrm{kg}$; BMI $23 \cdot 6(20 \cdot 9-28 \cdot 1) \mathrm{kg} / \mathrm{m}^{2}$.

The protocol for study 2 was similar to study 1 except that: (1) dose levels of $0(2 \times$ placebo puffers, two puffs of each twice daily), $800 \mu \mathrm{g} /$ day $(2 \times 100 \mu \mathrm{g}$ puffers, two puffs of each twice daily), and $1400 \mu \mathrm{g} /$ day $(1 \times 100 \mu \mathrm{g}$ and $1 \times 250 \mu \mathrm{g}$ puffer, two puffs of each twice daily) of BDP were used; and (2) the only samples taken were timed, fasting urine specimens over the first two hours after waking on the day before each dose interval and on the tenth day of treatment.

\section{LABORATORY METHODS}

Plasma cortisol and urine cortisol were measured by radioimmunoassay ("Quanticoat" cortisol kit, Kallestad Laboratories, Austin, Texas, USA). Urinary cortisol was expressed both as a ratio to the creatinine concentration of the specimen and as output/hour during the relevant collection period. Urinary creatinine was measured by standard methods. The $95 \%$ coefficient of variation of the urinary cortisol assay averaged $11.4 \%$ over the concentration range seen in the study, whilst that of the urinary creatinine assay averaged $6 \cdot 7 \%$.

\section{STATISTICAL METHODS}

Statistical analysis was performed using the CSS-Statistica software package (Stat-Soft, Tulsa, Oklahoma, USA). Results are presented as mean (95\% confidence interval (CI)). For each stage of the study the difference between predrug and postdrug values of the indices was calculated and analysis of variance for repeated measures (ANOVAR) was then used to compare these differences. Study 1 and study 2 were analysed separately. Significant differences ( $p<0.05$ on ANOVAR) were further examined using the least significant difference test.

\section{Results}

Subject compliance, assessed by weighing of the BDP canisters before and after each dosing interval, was excellent.

\section{STUDY 1}

Reference ranges (derived from the predrug studies) for the various indices of cortisol excretion are summarised in table 1 . Changes in urinary cortisol/creatinine (UCC) ratios, plasma cortisol, 24 hour urinary free cortisol excretion and timed cortisol outputs - that is, the difference between the values before and after administration of the drug - are summarised in table 2. Each subject's absolute values are shown in the figure. Combined UCC ratios and cortisol outputs from the first three hours after waking were also calculated but offered no additional insights and are thus not shown.

The placebo inhaler and BDP $800 \mu \mathrm{g} /$ day did not alter UCC ratios, 24 hour urinary free cortisol excretion or timed cortisol output. All indices of cortisol excretion were reduced during treatment with BDP $2000 \mu \mathrm{g} /$ day, although the changes in remainder of day UCC ratios and plasma cortisol levels were not statistically significant (table 2). Changes in cortisol output (nmol/hour) were similar to the UCC ratios.

Both in the basal state and during BDP therapy significant variation in the rate of cortisol excretion was noted in the four time periods

Table 1 Reference ranges (mean and 95\% confidence intervals) for indices of cortisol excretion derived from results of predrug studies

\begin{tabular}{|c|c|c|}
\hline & Mean & $95 \% C I$ \\
\hline \multicolumn{3}{|c|}{ (a) Cortisol/creatinine ratios $(\mathrm{nmol} / \mathrm{mmol})$} \\
\hline Hour 1 & $31 \cdot 1$ & $25 \cdot 0$ to $37 \cdot 2$ \\
\hline Hours 2 and 3 & $18 \cdot 2$ & $15 \cdot 2$ to $21 \cdot 4$ \\
\hline Remainder of day & $9 \cdot 3$ & $7 \cdot 8$ to $10 \cdot 9$ \\
\hline Overnight & $10 \cdot 8$ & $8 \cdot 8$ to $12 \cdot 8$ \\
\hline \multicolumn{2}{|l|}{ Study $2(n=30)$ : } & 20.5 to 31.4 \\
\hline \multicolumn{3}{|c|}{ (b) Timed cortisol outputs (mmol/hour) } \\
\hline Hour 1 & $21 \cdot 3$ & $16 \cdot 3$ to $26 \cdot 3$ \\
\hline Hours 2 and 3 & $14 \cdot 3$ & $11 \cdot 0$ to $17 \cdot 6$ \\
\hline Remainder of day & $5 \cdot 8$ & $4 \cdot 5$ to $7 \cdot 1$ \\
\hline Overnight & $6 \cdot 2$ & $4 \cdot 7$ to $7 \cdot 7$ \\
\hline \multicolumn{2}{|l|}{ Study $2(n=30)$} & $11 \cdot 3$ to $22 \cdot 1$ \\
\hline \multicolumn{3}{|c|}{ (c) Urinary free cortisol (nmol/day) } \\
\hline & $176 \cdot 4$ & $149 \cdot 8$ to $202 \cdot 9$ \\
\hline (d) Plasma cortisol at & $\begin{array}{r}n \text { nolll) } \\
309 \cdot 1\end{array}$ & 274.2 to 343.9 \\
\hline
\end{tabular}



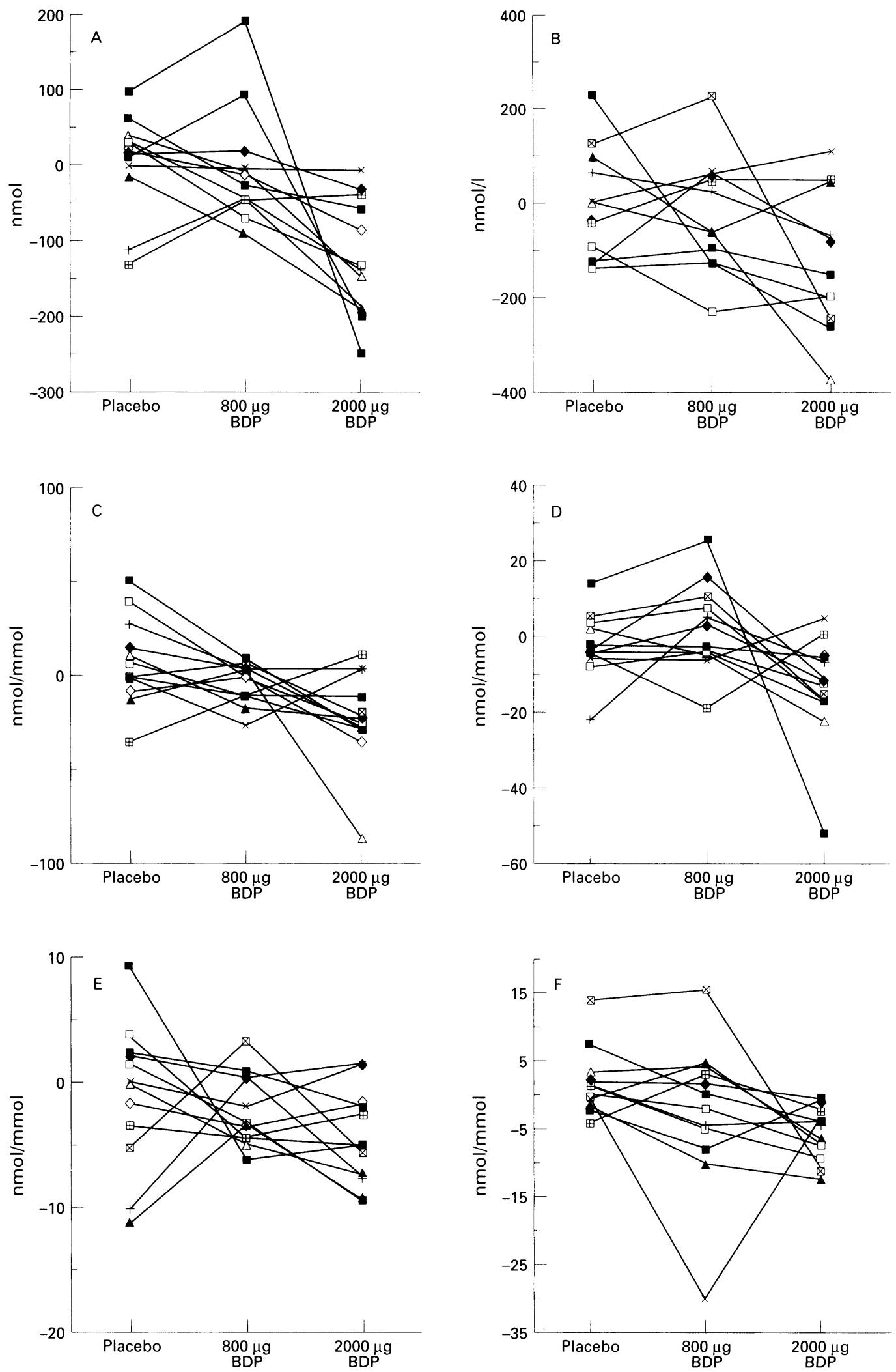

Individual data for study 1 showing $(A)$ changes in 24 hour urinary cortisol, (B) plasma cortisol levels at 09.00 hours and cortisol/creatinine ratios at $(C)$ hour $1,(D)$ hours 2 and 3, (E) remainder of day, and $(F)$ overnight following 10 days of treatment with placebo or beclomethasone dipropionate (BDP) $800 \mu \mathrm{g} /$ day and $2000 \mu \mathrm{g} /$ day.

sampled, with the order: hour $1>$ hours 2 and $3>$ remainder of day and overnight being observed for all indices measured (ANOVAR, $\mathrm{p}<0.001$ overall during each dose period, significant differences between all time periods except remainder of day and overnight). Thus, treatment with BDP did not abolish the normal circadian rhythm of cortisol excretion.

STUDY 2

This study (table 2, lower section) demonstrated reduced UCC ratios in urine taken 
Table 2 Mean (95\% CI) absolute changes (negative values represent a fall after drug treatment) in various indices of cortisol excretion following 10 days of treatment with placebo and beclomethasone dipropionate (BDP), 800 or $2000 \mu \mathrm{g} /$ day in 12 subjects (study 1), and BDP, 800 or $1400 \mu$ g/day in 10 subjects (study 2)

\begin{tabular}{|c|c|c|}
\hline Placebo & $800 \mu g B D P$ & $2000 \mu g B D P$ \\
\hline $\begin{array}{l}\text { Study } 1 \\
\begin{array}{ll}\text { (a) Changes in cortisol/creatinine ratios (nmol/mmol) } \\
\text { Hour 1 } & 8 \cdot 4(24 \cdot 9 \text { to }-8 \cdot 1) \\
\text { Hours } 2 \text { and } 3 & -2 \cdot 2(3 \cdot 9 \text { to }-8 \cdot 2) \\
\text { Remainder of day } & -1 \cdot 1(2 \cdot 9 \text { to }-5 \cdot 2) \\
\text { Overnight } & 2 \cdot 0(5 \cdot 4 \text { to }-1 \cdot 4)\end{array}\end{array}$ & $\begin{array}{l}-4 \cdot 1(2 \cdot 7 \text { to }-10 \cdot 9) \\
2 \cdot 1(9 \cdot 4 \text { to }-5 \cdot 2) \\
-2 \cdot 2(-0 \cdot 4 \text { to }-4 \cdot 04) \\
-2 \cdot 4(4 \cdot 6 \text { to }-9 \cdot 4)\end{array}$ & $\begin{array}{l}-21.9(-6.1 \text { to }-37 \cdot 8)^{b} \\
-13 \cdot 7(-4.6 \text { to }-22 \cdot 8)^{a} \\
-4 \cdot 3(-1.9 \text { to }-6 \cdot 7) \\
-5.4(-2.9 \text { to }-7.9)^{b}\end{array}$ \\
\hline 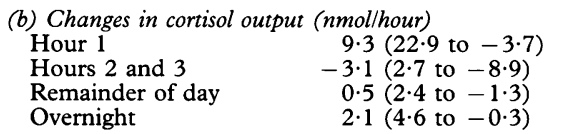 & $\begin{array}{r}2.4(6.8 \text { to }-1 \cdot 9) \\
-1.0(2 \cdot 8 \text { to }-4 \cdot 7) \\
0.6(6.3 \text { to }-5 \cdot 2) \\
-1 \cdot 1(1.4 \text { to }-3 \cdot 6)\end{array}$ & $\begin{array}{l}-18 \cdot 0(-4.5 \text { to }-31 \cdot 5)^{b} \\
-12.6(-1.7 \text { to }-23 \cdot 5) \\
-3 \cdot 6(-1 \cdot 1 \text { to }-6 \cdot 0) \\
-2 \cdot 8(-1.1 \text { to }-4 \cdot 5)^{h}\end{array}$ \\
\hline $\begin{array}{l}\text { (c) Changes in urinary free cortisol (nmol/day) } \\
5.0(51 \cdot 0 \text { to }-41 \cdot 0)\end{array}$ & $-1 \cdot 2(47 \cdot 0$ to $-49 \cdot 4)$ & $-119 \cdot 9(-70 \cdot 3 \text { to }-169 \cdot 5)^{b}$ \\
\hline $\begin{array}{r}\text { (d) Changes in plasma cortisol at } 0900 \text { hours }(\mathrm{nmol} / \mathrm{l}) \\
-4.5(85.9 \text { to }-95 \cdot 0)\end{array}$ & $-21 \cdot 1(55 \cdot 1$ to $-97 \cdot 3)$ & $-109 \cdot 4(-13.3$ to $-205 \cdot 5)$ \\
\hline Placebo & $800 \mu g B D P$ & $1400 \mu g B D P$ \\
\hline $\begin{array}{l}\text { Study } 2 \\
\begin{array}{l}\text { (a) Changes in cortisol/creatinine ratio ( } \mathrm{nmol} / \mathrm{mmol}) \\
\text { Hours } 1 \text { and } 2 \\
-3.0(3.5 \text { to }-9.6)\end{array}\end{array}$ & $-3 \cdot 7(5 \cdot 7$ to $-13 \cdot 0)$ & $-16.9(-4.3 \text { to }-29.5)^{a}$ \\
\hline $\begin{array}{l}\text { (b) Changes in cortisol output (nmol/hour) } \\
\text { Hours } 1 \text { and } 2 \\
-1.7(2 \cdot 2 \text { to }-5 \cdot 5)\end{array}$ & $-3.3(2.8$ to -9.5$)$ & $-13 \cdot 5(2 \cdot 7$ to $-29 \cdot 1)$ \\
\hline
\end{tabular}

${ }^{a} \mathrm{p}<0.05 ;{ }^{b} \mathrm{p}<0.01$ versus change with placebo.

two hours after waking in those treated with BDP $1400 \mu \mathrm{g} /$ day and confirmed the absence of an effect of BDP $800 \mu \mathrm{g} /$ day on this index. No significant changes in cortisol output (nmol/ hour) were demonstrated at this dose level.

\section{Discussion}

This study shows for the first time that UCC ratios, measured in timed urine samples, are as sensitive as the more cumbersome 24 hour urinary free cortisol excretion in demonstrating suppression of endogenous cortisol excretion during metered aerosol BDP treatment.

Our initial postulate was that cortisol excretion in urine samples taken soon after waking, being higher in the pretreatment state, would be more susceptible to subtle degrees of inhibition by inhaled BDP. Our results, as summarised in table 2, suggest that morning specimens, overnight specimens, and 24 hour collections may all be used to document changes in cortisol excretion during treatment with BDP at a dose of $2000 \mu \mathrm{g} /$ day. Measurement of actual cortisol output does not increase sensitivity, obviating the need for precise timing of the specimens.

The changes observed in these studies per se could represent either a homeostatic diminution in endogenous cortisol excretion in response to inhaled BDP, or pathological HPA suppression. This distinction is not clinically important during short term treatment, but becomes very relevant in chronic therapy with high dose BDP. Dynamic testing using metyrapone ${ }^{2}$ or insulin hypoglycaemia ${ }^{10}$ has shown reduced HPA response to stress during BDP therapy, suggesting that these effects may be more than a simple short term adaptive response: It is important to note that mild HPA suppression may occur with doses of inhaled cortisosteroid that do not cause clinically detectable systemic effects. Indeed, the suppression of endogenous cortisol secretion in this setting may protect the subject against net glucocorticoid excess.
Study 2 demonstrated a significant effect of BDP $1400 \mu \mathrm{g} /$ day on the morning UCC ratio, with no effect of BDP $800 \mu \mathrm{g} / \mathrm{day}$, suggesting that the threshold for inhibition of morning cortisol excretion lies between these dose levels. In one recent study using inhaled fluticasone ${ }^{14}$ the greatest changes in plasma cortisol concentrations were seen in overnight samples. For repeated testing, overnight or early morning collections are likely to prove more convenient, allowing subjects to collect the specimens at home without interfering with daytime activities.

In summary, UCC ratios in timed urine samples are as sensitive as more traditional measures such as 24 hour urinary free cortisol excretion in detecting the effects of inhaled steroid therapy on endogenous cortisol secretion, and offer practical advantages which obviate the need for accurate measurement of urine volume and for complete 24 hour collections. The necessity for urine collections to be made in the fasting state cannot be definitively assessed using our data.

Further work is required to define more clearly the reference ranges and day to day variability for the overnight and post-waking UCC ratios, both in normal and asthmatic subjects, in order to assess the usefulness of a single result in an individual patient in detecting significant HPA suppression.

Metered dose inhalers were supplied by Allen and Hanburys, Australia.

1 Busse W. Asthma in the 1990s. A new approach to therapy. Postgrad Med 1992;92:177-90.

2 Teelucksingh S, Padfield PL, Tibi L, Gough KJ, Holt PR. Inhaled corticosteroids, bone formation, and osteocalcin [letter] [see comments]. Lancet 1991;338:60-1.

3 Leech JA, Hodder RV, Ooi DS, Gay J. Effects of short-term inhaled budesonide and beclomethasone dipropionate on inhaled budesonide and beclomethasone dipropionate on
serum osteocalcin in premenopausal women. Am Rev serum osteocalcin in prem.

4 Holt PR, Lowndes DW, Smithies E, Dixon GT. The effect of an inhaled steroid on the hypothalamic-pituitary-adrenal axis - which tests should be used? Clin Exp Allergy 1990;20:145-9.

5 Selroos O, Hulme $M$. Effect of a volumatic spacer and mouth rinsing on systemic absorption of inhaled corticosteroids from a metered dose inhaler and dry powder inhaler. Thorax 1991;46:891-4. 
6 Prahl P. Adrenocortical suppression following treatment with beclomethasone and budesonide. Clin Exp Allergy 1991;21:145-6.

7 Brown PH, Blundell G, Greening AP, Crompton GK. Do large volume spacer devices reduce the systemic effects of high dose inhaled corticosteroids?. Thorax 1990;45:736-9.

8 Brown PH, Blundell G, Greening AP, Crompton GK. Hypothalamo-pituitary-adrenal axis suppression in asthmatics inhaling high dose corticosteroids. Respir Med 1991;85:501 10 .

9 Teelucksingh S, Padfield PL, Dicker I, Holt PR. A doubleblind placebo controlled crossover study of effects upon the hypothalamic-pituitary-adrenal axis of beclothe hypothalamic-pituitary-adrenal axis of beclomethasone dipropionate metered dose inhaler at $100 \mathrm{mcg}$,
$200 \mathrm{mcg}, 350 \mathrm{mcg}$ and $500 \mathrm{mcg}$ four times daily in healthy adults. Am Rev Respir Dis 1991;143:A626 (abstract).

10 Brown PH, Blundell G, Greening AP, Crompton GK. Screening for hypothalamo-pituitary-adrenal axis suppression in asthmatics taking high dose inhaled corticosteroids. Respir Med 1991;85:511-6.

11 Brown PH, Greening AP, Crompton GK. Hypothalamopituitary-adrenal axis suppression in asthmatic adults taking high dose beclomethasone dipropionate. $\mathrm{Br} f \mathrm{Clin}$ Pract 1992;46:102-4.

12 Farrer M, Francis AJ, Pearce SJ. Morning serum cortisol concentrations after $2 \mathrm{mg}$ inhaled beclomethasone dipropionate in normal subjects: effect of a $750 \mathrm{ml}$ spacing device. Thorax 1990;45:740-2.

13 Contreras LN, Hane S, Tyrrell JB. Urinary cortisol in the assessment of pituitary-adrenalfunction: utility of 24-hour assessment of pituitary-adrenalfunction: utility of 24-hour 62:965-9.

14 Grahnen A, Eckernas SA, Brundin RM, Ling-Andersson A. An assessment of the systemic activity of single doses of inhaled fluticasone propionate in healthy volunteers Br f Clin Pharmacol 1994;38:521-5. 